\begin{tabular}{|c|c|c|}
\hline \multirow{3}{*}{$\begin{array}{l}\text { ITC 3/46 } \\
\text { Journal of Information Technology } \\
\text { and Control } \\
\text { Vol. 46/ No.3/ } 2017 \\
\text { pp. 395-402 } \\
\text { DOI 10.5755/j01.itc.46.3.16197 } \\
\text { ๑ Kaunas University of Technology }\end{array}$} & \multicolumn{2}{|c|}{$\begin{array}{l}\text { Performance of Quasi-Logarithmic Quantizer } \\
\text { for Discrete Input Signal }\end{array}$} \\
\hline & Received 2016/09/06 & Accepted after revision 2017/07/19 \\
\hline & \multicolumn{2}{|c|}{ crossef http://dx.doi.org/10.5755/j01.itc.46.3.16197 } \\
\hline
\end{tabular}

\title{
Performance of Quasi-Logarithmic Quantizer for Discrete Input Signal
}

\section{Milan Ž. Tančić, Zoran H. Perić, Nikola Simić, Stefan S. Tomić}

Faculty of Electronic Engineering, University of Niš, Department of Telecommunications, Serbia Aleksandra Medvedeva 14, 18000, Niš, Serbia, e-mail:milan_tancic@yahoo.com, zoran.peric@elfak.ni.ac.rs, simicnikola90@gmail.com, stefan@elfak.rs

Corresponding author: milan_tancic@yahoo.com

In this paper, the performance of quasi-logarithmic quantizer, designed for correlated discrete input signal is analyzed. Quantizer design is done for Laplacian source due to its both hardware and software significance, whereas experiments are done by processing test wideband speech signal sampled at $16[\mathrm{kHz}]$. The quantizer is exploited as a second stage of two-stage quantization system, where the first step is used for continuous signal sampling, while the second stage provides additional data compression. The main goal is to provide improved design by discussing theoretical performance of two quantization models. As the traditional models for performance estimation provide estimation of average performance, we have decided to propose a novel model for performance estimation and to analyze performance in details for each random input signal variance. Finally, the experimental results have shown excellent matching with theoretical results.

KEYWORDS: discretized input signal, Laplacian source, $\mu$-law quantization, speech signal processing.

\section{Introduction}

Speech signal processing as a one of the most important areas in telecommunications is very well researched and a lot of digitization systems are proposed and implemented [1, 4-5]. However, the authors usually pay attention only on the system design, whereas there are not many developed theoretical models which estimate system performance. Furthermore, comparison is usually done experimen- tally, while theoretical comparisons are done as the average performance for the range of input signal variances [9, 12-13].

Mismatch quantization is a well-known technique that is used for processing different types of signals. Generally, it consists of two steps and a lot of solutions were discussed in recent years $[6-8,10]$. Commonly, the first step is used for region determination 
while the levels within it are defined in the second quantization step. However, another design of twostage mismatch quantization, where the basic analysis and design of two-stage mismatch quantization model are provided for uniform and non-uniform quantizer application, was proposed in [14]. The first step in such analog speech signal digitization system is rough quantization with a large number of quantization levels, which provides discrete samples at the output [14]. After that, discrete samples are further quantized using a quantizer with a small number of quantization levels in order to provide additional compression. Since discrete signal's amplitude is limited, the overload distortion does not exist. However, non-stationary signals, including wideband speech signal, are quantized very often by using non-uniform quantizers due to high reconstructed signal quality.

As the system exploits optimal compandor for processing the signal of Laplacian source [14], the main idea of this paper is to discuss implementation of different quantization model, particularly quasi-logarithmic quantizer in the second stage and to analyze the system performance for speech signal processing. The motivation for applying quasi-logarithmic quantizers in the proposed model comes from the fact that logarithmic quantizers have better robustness than optimal compandor across a wide range of speech signal variances and because of that they are more suitable for discrete signal processing [3].

Usually, performance is estimated using the variance of continuous input signal, whereas changes after the first stage are neglected. Moreover, it is a common phenomenon that information about continuous entrance is unknown and that information about discretized signal exists, only. In this paper, it is shown that information about discrete variance after the first stage in the proposed two-stage system is very important. Finally, we propose a novel model for performance estimation for both aforementioned systems. The model provides detailed results for each single variance within the observed range, instead of traditional average performance. In the end, we propose a model for comparison with experimental results. For such a task, experimental results are obtained by processing recorded benchmark.

According to [2], the best ratio between complexity and quality can be achieved in the case when the first quantization step is designed for at least 4 bits per sample more quantization levels than the second one. Consequently, the analysis we perform takes into account this recommendation, but we analyze system for less difference, too.

The paper is organized as follows. Section 2 describes design of quasi-logarithmic quantizer for discrete input signal in details as well as two-stage quantization model. In Section 3, an algorithm for experimental analysis of wideband speech signal processing is described. In addition, an assessment which includes novel comparison between theoretical and experimental results as well as results obtained by using optimal compandor in the second stage of the model, described in [14], is performed. Finally, the obtained results are summarized and some future plans are discussed in Section 4.

\section{Quasi-logarithmic quantizer design for discrete input signal}

The aim of this section is to describe a two-stage quantization model by using quasi-logarithmic quantizers for discrete input signal. In the first step, A/D conversion is performed using a quantizer with a high number of quntization levels, whose purpose is to convert analog signal to discrete samples, whereas the quantizer $Q_{1}$ provides additional data compression in the second step [14].

As the analysis of non-stationary speech signal is performed, it is suitable to use non-uniform quantizer $Q_{0}$ for discretization $[3,15]$. Thus, $\mu$-law quantization is employed $[2-3,15]$. This way, continuous input signal is quantized by using quasi-logarithmic quantizer $Q_{0}$ with $N_{0}$ output levels $\left(N_{0}=256\right)$. Furthermore, speech signal can be modeled using Laplacian probability density function, defined with:

$$
p(x)=\frac{1}{\sqrt{2} \sigma} \exp \left(-\frac{|x| \sqrt{2}}{\sigma}\right),
$$

where $\sigma$ represents standard deviation.

Model of two-stage quantization system with the number of quantization levels that we discuss is presented in Fig. 1. 
Figure 1

The two-stage quantization system

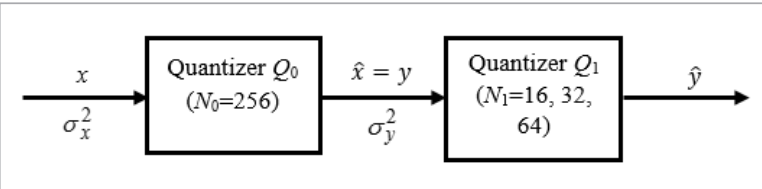

Next, the compressor function using $\mu$-law compression is defined with $[3,11,15]$ :

$$
c(x)=\frac{x_{\max }}{\ln (1+\mu)} \ln \left(1+\mu \frac{|x|}{x_{\max }}\right) \operatorname{sgn}(x), \quad|x| \leq x_{\max },
$$

where $x_{\max }$ is maximal amplitude of quasi-logarithmic quantizer $Q_{0}$, which depends on the range of the input signal, whereas $\mu$ is compression factor. According to $\mu$-logarithmic compression function, decision thresholds $x_{\mathrm{i}}$ and representation levels $y_{\mathrm{i}}$ are calculated as $[3,11,15]$ :

$$
x_{i}=\frac{x_{\max }}{\mu}\left(\exp \left(\frac{2 i}{N_{0}} \ln (1+\mu)\right)-1\right), i=1,2, \ldots, N_{0},
$$

$$
y_{i}=\frac{x_{\max }}{\mu}\left(\exp \left(\frac{2(i-0.5)}{N_{0}} \ln (1+\mu)\right)-1\right), i=1,2, \ldots, N_{0} .
$$

Next, variance of continuous signal $\sigma_{\mathrm{x}}^{2}$ takes values from the range $(-30[\mathrm{~dB}], 30[\mathrm{~dB}])$ and converts to real values using Eq. (5), while expression Eq. (6) is used for calculating discrete signal variance $\sigma_{\mathrm{y}}^{2}$ [3]:

$$
\sigma_{x}^{2}=\sigma_{\text {reff }}^{2} \cdot 10^{\frac{\sigma_{x}^{2}[\mathrm{~dB}]}{10}},
$$

$$
\sigma_{y}^{2}=2 \cdot \sum_{i=1}^{N_{0} / 2} y_{i}^{2} \cdot P_{i},
$$

where $\sigma_{\text {reff }}^{2}$ represents referent variance, whereas $P_{i}$ represent probabilities of discrete input levels of quantizer $Q_{1}$. It should be noted that for calculating $\sigma_{\mathrm{y}}{ }^{2}$ in Eq. (6) it is used $\sigma=\sigma_{x}$. Probabilities $P_{i}$ are defined as $[3,14]$ :

$$
P_{i}=\int_{x_{i}}^{x_{i+1}} p(x) d x=\frac{1}{2}\left(\exp \left(-\frac{\sqrt{2} \cdot x_{i}}{\sigma_{x}}\right)-\exp \left(-\frac{\sqrt{2} \cdot x_{i+1}}{\sigma_{x}}\right)\right) .
$$

The aim of the second stage is to provide additional signal compression by using a low number of quantization levels. Discretized output signal of the quantizer $Q_{0}$ is lead to the $Q_{1}$ quantizer's entrance. As the discretized signal remains non-stationary, it is convenient to use quasi-logarithmic quantizer for this task, too. However, the second-stage quantizer $Q_{1}$ should be designed for a low number of quantization levels and its decision thresholds $t_{i}$ and representational levels $w_{i}$ are defined with $[3,15]$ :

$t_{i}=\frac{x_{\max 1}}{\mu_{1}}\left(\exp \left(\frac{2 i}{N_{1}} \ln \left(1+\mu_{1}\right)\right)-1\right), i=1,2, \ldots, N_{1}$,

$w_{i}=\frac{x_{\max 1}}{\mu_{1}}\left(\exp \left(\frac{2(i-0.5)}{N_{1}} \ln \left(1+\mu_{1}\right)\right)-1\right), i=1,2, \ldots, N_{1}$,

where $x_{\max 1}$ is maximal amplitude of quantizer $Q_{1}$ while $N_{1}$ is the number of quantization levels $\left(N_{0}>N_{1}\right)$. Since the quantizers $Q_{0}$ and $Q_{1}$ are symmetric, we have described just the positive range of the signal processing system using Eqs. (3)-(4) and Eqs. (8)-(9).

\section{Theoretical and experimental results}

In this section, we make a comparison between traditional modeling which only exploits the information about continuous signal variance $\left(\sigma_{x}^{2}\right)$ and the proposed two-stage model which also exploits the information about discrete variance $\left(\sigma_{y}^{2}\right)$. Furthermore, these theoretical results are compared with the experimental results obtained by processing benchmark test wideband speech signal sampled at 16 [kHz]. In the end, the results obtained using this proposed speech signal processing model are compared with the results presented by a different model [14], where uniform quantizer and optimal compandor are implemented in the first and the second stage, respectively, instead of quasi-logarithmic quantizers. A discussion is done for $N_{0}=256$ quantization levels at the first stage $\left(R_{0}=8\right.$ [bits/sample]) and compression factor $\mu_{0}=255$, whereas second stage parameters are $R_{1} \in(4,5,6)$ [bits/sample] while compression factor is $\mu_{1} \in(20,255)$. The algorithm for signal processing is shown in Fig. 2.

In order to measure the quality of the reconstructed signal, we analyze signal distortion and signal-to-qu- 
Figure 2

The algorithm for proposed speech signal processing model

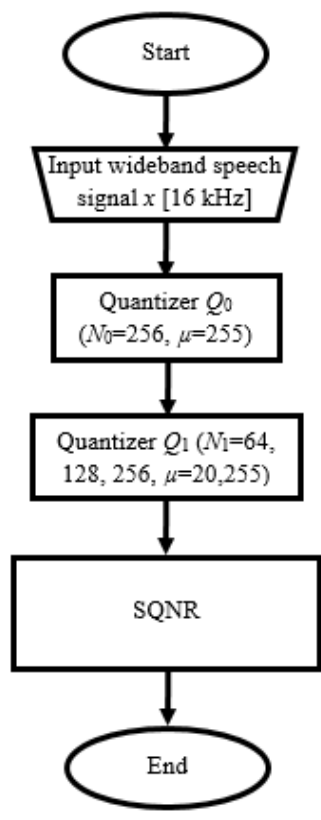

antization-noise ratio (SQNR). For the observed system, total distortion is equal to granular distortion, since discrete signal is limited by amplitude after the first-stage [9]:

$$
D_{t}\left(\sigma_{y}^{2}(j)\right)=2 \sum_{i=N_{1} / 2}^{N_{1}} \sum_{j=1}^{r_{i}}\left(y_{i j}-w_{i}\right)^{2} \cdot P\left(y_{i j}\right),
$$

where parameter $r_{i}$ denotes the number of input levels mapped with $w_{i}$, whereas $y_{i j}$ are output levels of quantizer $Q_{0}$, while $N_{1}$ represents the number of quantization levels of quantizer $Q_{1}$.

The quality of reconstructed signal is measured using SQNR, which represents the standard measure $[2-3,15]$ :

$$
\mathrm{SQNR}[\mathrm{dB}]=10 \cdot \log _{10}\left(\frac{\sigma_{y}^{2}}{D_{t}}\right)
$$

Design improvements and determination of system parameters are based on a novel model for comparison between experimental and theoretical results for each variance. The model processes signal as follows. Firstly, as an input signal it is used a wideband speech signal and it is sampled at $16[\mathrm{kHz}]$. Next, signal dynamics is calculated by dividing the whole signal into frames of 240 samples and by determining the highest and lowest variance of a frame as:

$$
B[\mathrm{~dB}]=10 \cdot \log \left(\frac{\sigma_{\max }^{2}(M)}{\sigma_{\min }^{2}(M)}\right),
$$

where $\sigma_{\max }^{2}$ and $\sigma_{\min }^{2}$ represent highest and lowest signal variance, whereas $B$ is signal dynamics.

In order to provide an adequate comparison, referent variance is equal to $0[\mathrm{~dB}]$, as it is a common case, and it is chosen at the half of the dynamic range, while maximal and minimal variance values define variance range in the following way:

$\sigma_{\max }^{2}[\mathrm{~dB}]=\frac{B}{2}$

Moreover, support range has to be adapted as:

$x_{\max }=x_{\max }^{\left(\sigma^{2}=1\right)} \cdot \sigma_{\text {reff }}$.

where $x_{\max }^{\left(\sigma^{2}=1\right)}$ represents optimal support limit value in the case of modeling speech signal with Laplacian probability density function, shown in Eq. (1), and it is obtained by using closed-form formula, which is defined as [11]:

$x_{\max }^{\left(\sigma^{2}=1\right)}=\frac{1}{\sqrt{2}} \cdot \ln \left(\frac{3 \cdot \mu \cdot N^{2}}{\ln ^{2}(\mu+1)}\right)$,

where $\mu$ is the compression factor while $N$ presents the number of quantization levels. For experimental analysis, we have used a wideband speech signal (sampled at $16[\mathrm{kHz}])$, recorded in Laboratory of Acoustics at Faculty of Electronic Engineering, University of Nis. The measured continuous variance of recorded test signal is $\sigma_{x}^{2}=0.0021$. Taking into account Eqs. (12)-(13), we have obtained $\sigma_{\text {reff }}^{2}=5.84 \cdot 10^{-5}$ whereas the signal dynamics is around 54 [dB]. Furthermore, the obtained support value for $Q_{0}$ is fixed and equal to 0.0775 for all observed cases, whereas the optimal support values for $Q_{1}$ have different values depending on the system parameters, as the system design de- 
pends on the compression factor $\mu$ and the number of quantization levels $N$, while the adaptation is not applied within frames. The obtained support values for quantizer $Q_{1}$ are between $0.0394(\mathrm{R}=4$ bits/sample; $\mu=20)$ and 0.0623 ( $\mathrm{R}=6$ bits/sample; $\mu=255$ ). As the referent variance is very low, experimental comparison for a set of variances is done as follows. The range of interest is $(-30[\mathrm{~dB}], 30[\mathrm{~dB}])$. For the purpose of comparison, the range is divided into sub-ranges with the step of $2[\mathrm{~dB}]$, whereas input signal is divided into frames of 240 samples, as for variance determination. Then, for each segment, parameter $L_{i}$ is calculated as:

$$
L_{i}[\mathrm{~dB}]=10 \cdot \log \left(\frac{\hat{\sigma}_{y_{i}}^{2}}{\sigma_{\text {reff }}^{2}}\right),
$$

where $\hat{\sigma}_{y_{i}}^{2}$ is the variance level of the $i^{\text {th }}$ segment. After determining $L_{i}$, quantization is performed both ways - for traditional one-stage system, continuous signal is quantized with $R=4,5,6$ [bits/sample], whereas for the proposed two-stage system parameters are $R_{0}=8$ [bits/sample] and $R_{1}=4,5,6$ [bits/sample]. For each segment of the range, the number of frame appearances was measured for the observed variance. After that, the mean SQNR value of all frames that are located in a certain frame is calculated, for both continuous and discretized signal. These mean SQNR values per segment are marked as SQNR $\left(L_{i}\right)$ in [dB], and shown on the ordinate in the Figs. 3-4. SQNR $\left(L_{i}\right)$ presents the average SQNR in $[\mathrm{dB}]$ for the $i^{\text {th }}$ segment, and it is defined as:
$\left.\operatorname{SQNR}\left(L_{i}\right)[\mathrm{dB}]=\frac{1}{M_{i}} \sum_{k=1}^{M_{i}} \operatorname{SQNR}\left(\sigma_{y_{i k}}^{2}\right) \mathrm{dB}\right]$

while the average value of SQNR for a wide dynamic range is obtained using:

$$
\left.\mathrm{SQNR}_{\mathrm{avg}}[\mathrm{dB}]=\frac{1}{L} \sum_{k=1}^{L} \operatorname{SQNR}\left(\sigma_{y_{k}}^{2}\right) \mathrm{dB}\right] \text {. }
$$

This way, a new method for obtaining quality measure, suitable for comparing theoretical and experimental results, is introduced. The standard average quality measure $\mathrm{SQNR}_{\text {avg }}$ from Eq.(11) in a wide range is defined as follows:

$$
\operatorname{SQNR}_{\mathrm{avg}}[\mathrm{dB}]=\frac{1}{F} \sum_{k=1}^{F} \operatorname{SQNR}(k)[\mathrm{dB}],
$$

where $F$ is the total number of frames defined as:

$$
F=\sum_{i=1}^{L} M(i),
$$

where $M(i)$ is the number of frames placed into the segment $i$.

In Figs. 3-4, SQNR for a wide range of input signal variances depending on compression factor $\mu$ is presented. In the end, the average SQNR is calculated as in traditional models and it is shown in Table 1.

\section{Figure 3}

SQNR for wide range of input signal variances $(\mu=20)$ : a) Experimental results; b) Theoretical results
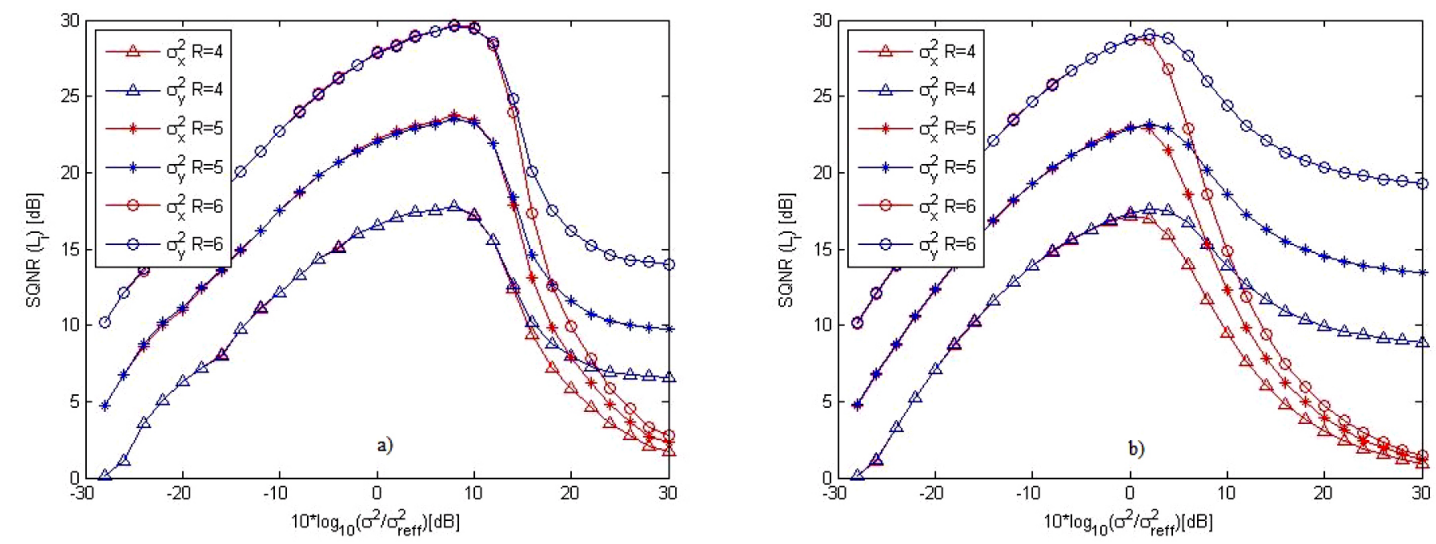


\section{Figure 4}

SQNR for wide range of input signal variances ( $\mu=255)$ : a) Experimental results; b) Theoretical results
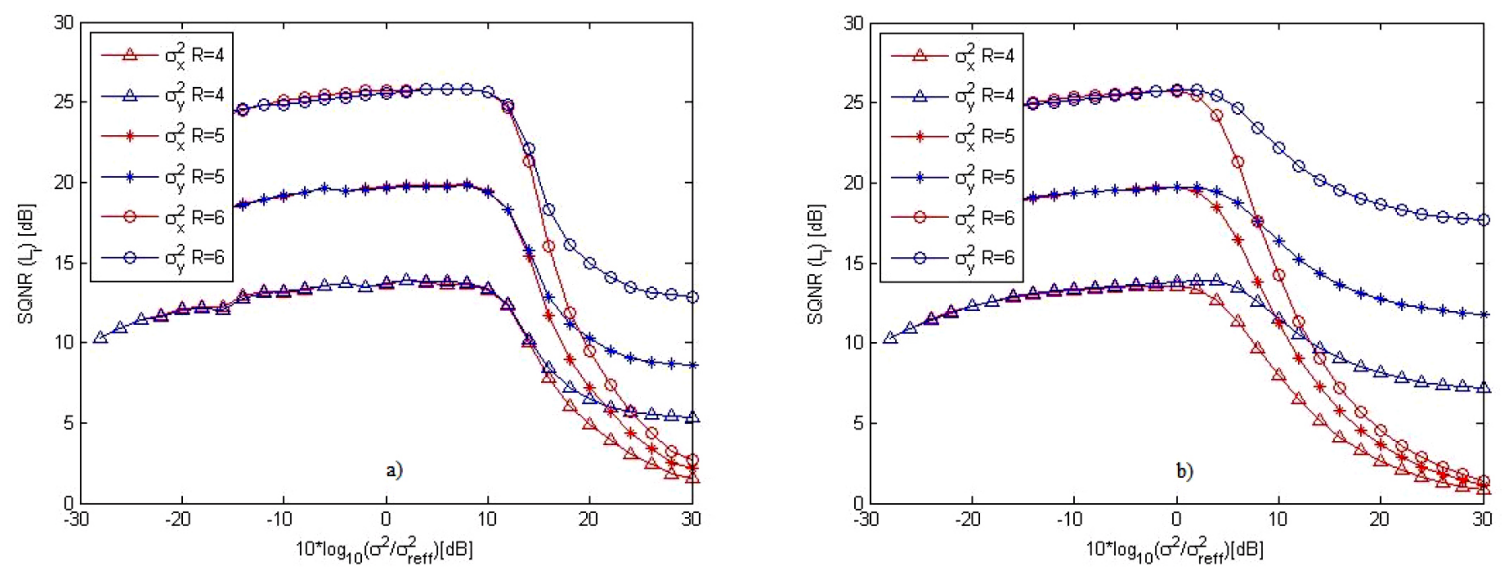

Table 1

Average SQNR for wide range of variances (-30 [dB], $30[\mathrm{~dB}])$

\begin{tabular}{|c|c|c|c|c|c|}
\hline \multirow{2}{*}{ R [bits/sample] } & \multirow{2}{*}{$\mu$} & \multicolumn{2}{|c|}{ Proposed theoretical model } & \multicolumn{2}{|c|}{ Experimental results } \\
\hline & & $\mathrm{SQNR}_{\mathrm{av}}^{\mathrm{cont}}$ & $\mathrm{SQNR}_{\mathrm{av}}^{\text {disc }}$ & $\mathrm{SQNR}_{\mathrm{av}}^{\mathrm{cont}}$ & $\mathrm{SQNR}_{\mathrm{av}}^{\text {disc }}$ \\
\hline \multirow{2}{*}{4} & 20 & 8.5352 & 11.2632 & 9.7321 & 10.5400 \\
\hline & 255 & 9.0984 & 11.2908 & 10.3218 & 10.9580 \\
\hline \multirow{2}{*}{5} & 20 & 12.3055 & 16.3280 & 14.1703 & 15.4675 \\
\hline & 255 & 13.2782 & 16.6781 & 15.1109 & 16.2019 \\
\hline \multirow{2}{*}{6} & 20 & 16.0018 & 21.9298 & 18.6834 & 20.7717 \\
\hline & 255 & 17.3339 & 22.5549 & 19.9489 & 21.7933 \\
\hline
\end{tabular}

By observing Figs. 3-4, an excellent matching between theoretical and experimental results for the wide range of variances can be noticed.

Moreover, a slightly different nature of one-stage and two-stage models can be observed by focusing on high variances as the big difference is achieved for both theoretical and experimental results. In the end, it can be seen that by increasing the bit-rate $R, \mathrm{SQNR}$ increases, too, as it could be expected.

By observing Table 1, we can conclude that the average performance of the proposed theoretical model is very close to the average experimental results and that experimental and theoretical results follow pa- rameters changing in the same manner. Moreover, it can be noticed that the average difference between theoretical and experimental results is 1.3 [dB]. It can also easily be seen that the average results for discrete input signal are 2.2-5.2 [dB] higher in the threoretical analysis and 0.6-2.1 [dB] higher in the experimental analysis, depending on bit-rate and compression factor value.

In order to make an appropriate comparison with system described in [14], the analysis is also performed for the range (-20 [dB], $20[\mathrm{~dB}])$. The two-stage system for speech signal processing, described in [14], instead of quasi-logarithmic quantizers at both stages 
of the model, consists of the fixed uniform quantizer $Q_{1}$, which converts analog signal to discrete samples at the first stage, and the optimal compandor $Q_{2}$, which performs additional compression, at the second stage. The quantizer at the second stage of the system in [14] is designed for bit rates $R_{2}=4,5$ [bits/sample]. Thus, the analysis is done for these bit rates and the results are presented in Table 2 .

The results shown in Table 2 confirm suitability of exploiting quasi-logarithmic quantizer in the se- cond stage of system, because of their robustness in a wide range of variances. The usage of quasi-logarithmic quantizers instead of optimal compandor, as it was performed in [14], provides about $1[\mathrm{~dB}]$ higher SQNR, comparing theoretically obtained discrete results to the results in [14], for both bit-rates in the case of compression factor value $\mu=20$, and $0.3-0.6$ [dB] higher SQNR, comparing experimentally obtained discrete results to those in [14], for both bit-rates in the case of compression factor value $\mu=20$.

Table 2

The average SQNR for wide range of variances $(-20$ [dB], 20 [dB])

\begin{tabular}{|c|c|c|c|c|c|c|c|}
\hline \multirow{2}{*}{ R [bits/sample] } & \multirow{2}{*}{$\mu$} & \multicolumn{2}{|c|}{ The proposed theoretical model } & \multicolumn{2}{|c|}{ Experimental results } & \multicolumn{2}{|c|}{ Results from [14] } \\
\hline & & $\mathrm{SQNR}_{\mathrm{av}}^{\mathrm{cont}}$ & $\mathrm{SQNR}_{\mathrm{av}}^{\mathrm{disc}}$ & $\mathrm{SQNR}_{\mathrm{av}}^{\text {cont }}$ & $\mathrm{SQNR}_{\mathrm{av}}^{\mathrm{disc}}$ & $\mathrm{SQNR}_{\text {av }}^{\text {cont }}$ & $\mathrm{SQNR}_{\mathrm{av}}^{\mathrm{disc}}$ \\
\hline \multirow{2}{*}{4} & 20 & 11.7611 & 13.6013 & 12.7228 & 12.9509 & \multirow{2}{*}{11.0023} & \multirow{2}{*}{12.6012} \\
\hline & 255 & 10.9442 & 12.4421 & 12.0344 & 12.2179 & & \\
\hline \multirow{2}{*}{5} & 20 & 16.2082 & 18.7768 & 17.8673 & 18.2416 & \multirow{2}{*}{15.6085} & \multirow{2}{*}{17.6616} \\
\hline & 255 & 15.8721 & 17.9857 & 17.5601 & 17.8639 & & \\
\hline
\end{tabular}

\section{Conclusions}

In this paper, we have analysed design of quasi-logarithmic quantizer for discrete input signal and its performance for speech signal processing. We have demonstrated that modelling, which exploits only the information about continuous signal variance, has limitations for high variances. Consequently, we have shown that information about discrete variance after the first stage of two-stage quantization system is very important. We have demonstrated that it is more suitable to use quasi-logarithmic quantizer for discrete signal processing than the optimal compandor across the wide range of variances. In the end, we have proposed a novel method for comparing experimental and theoretical results, which provides excellent matching between experimental results, obtained by processing test speech signal, and theoretically estimated performance.

\section{Acknowledgments}

This work is supported by Serbian Ministry of Education, Science and Technologic Development (Project TR 32035).

\section{References}

1. Chen, K.-Y., Liu, S.-H., Chen, B. Exploring the Use of Unsupervised Query Modeling Techniques for Speech Recognition and Summarization. Speech Communication, 2016, 80, 49-59. http://dx.doi.org/10.1016/j. specom.2016.03.006
2. Gray, R. M., Neuhoff, D. L. Quantizaton. IEEE Transactions on Information Theory, 1998, 44 (6), 2325-2383. http://dx.doi.org/10.1109/18.720541

3. Jayant, N. S., Noll, P. Digital Coding of Waveforms. New Jersey, Prentice Hall, Chapter 5, 1984, 221-251. 
4. Lin, T.-H., Yeh, C.-Y., Hwang, S.-H. Efficient Statistics-Based Algebraic Codebook Search Algorithms Derived from RCM for an ACELP Speech Coder. Information Technology and Control, 2015, 44(4), 410-419. http://dx.doi.org/10.5755/j01.itc.44.4.9847

5. Mavaddaty, S., Ahadi, S. M., Seyedin, S. A Novel Speech Enhancement Method by Learnable Sparse and Low-Rank Decomposition and Domain Adaptation. Speech Communication, 2016, 76, 42-60. http://dx.doi. org/10.1016/j.specom.2015.11.003

6. Na, S. Asymptotic Formulas for Mismatched FixedRate Minimum MSE Laplacian Quantizers. IEEE Signal Processing Letters, 2008, 15, 13-16. http://dx.doi. org/10.1109/LSP.2007.910240

7. Na, S. Asymptotic Formulas for Variance-Mismatched Fixed-Rate Scalar Quantization of a Gaussian Source. IEEE Transactions on Signal Processing, 2011, 59(5), 2437-2441. http://dx.doi.org/10.1109/ TSP.2011.2112354

8. Na, S., Neuhoff, D. L. Asymptotic MSE Distortion of Mismatched Uniform Scalar Quantization. IEEE Transactions on Information Theory, 2012, 58(5), 31693181. http://dx.doi.org/10.1109/TIT.2011.2179843

9. Nikolic, J., Peric, Z. Lloyd-Max's Algorithm Implementation in Speech Coding Algorithm Based on Forward
Adaptive Technique. Informatica, 2008, 19(2), 255-270. http://www.mii.lt/Informatica/pdf/INFO712.pdf

10. Nikolic, J., Peric, Z., Jovanovic, A. Variance Mismatch Analysis of Unrestricted Polar Quantization for Gaussian Source. IEEE Signal Processing Letters, 2014, 21(5), 540-544. http://dx.doi.org/10.1109/LSP.2014.2309093

11. Peric, Z., Aleksic, D., Stefanovic, M., Nikolic, J. New Approach to Support Region Determination of the $\mu$-Law Quantizer. Elektronika Ir Elektrotechnika, 2013, 19(8), 2013, 111-114. http://dx.doi.org/10.5755/j01.eee.19.8.5406

12. Peric, Z., Nikolic, J., Mosic, A., Panic, S. A Switc-hed-Adaptive Quatization Technique Using $\mu$-Law Quantizers. Information Technology and Control, 2010, 39(4), 317-320. http://www.itc.ktu.lt/index.php/ITC/article/view/12388

13. Peric, Z., Nikolic, J., Mosic, A., Petkovic, M. Design of Fixed and Adaptive Companding Quantizer with Variable-Length Codeword for Memoryless Gaussian Source. Informatica, 2013, 24(1), 71-86. http://www. mii.lt/informatica/htm/INFO888.html

14. Peric, Z., Simic, N., Savic, M. Analysis and Design of Two Stage Mismatch Quantizer for Laplacian Source. Elektronika Ir Elektrotechnika, 2015, 21 (3), 49-53. http://dx.doi.org/10.5755/j01.eee.21.3.10380

15. Sayood, K. Introduction to Data Compression. Elsevier Inc., $3^{\text {rd }} \mathrm{ed}, 2005$.

\section{Summary / Santrauka}

In this paper, the performance of quasi-logarithmic quantizer, designed for correlated discrete input signal is analyzed. Quantizer design is done for Laplacian source due to its both hardware and software significance, whereas experiments are done by processing test wideband speech signal sampled at 16 [kHz]. The quantizer is exploited as a second stage of two-stage quantization system, where the first step is used for continuous signal sampling, while the second stage provides additional data compression. The main goal is to provide improved design by discussing theoretical performance of two quantization models. As the traditional models for performance estimation provide estimation of average performance, we have decided to propose a novel model for performance estimation and to analyze performance in details for each random input signal variance. Finally, the experimental results have shown excellent matching with theoretical results.

Straipsnyje analizuojamas koreliuotam diskrečiajam ièjimo signalui skirto kvazilogaritminio kvantizatoriaus našumas. Laplaso šaltiniui pritaikytas kvantizatoriaus dizainas dèl jo techninès ir programinės įrangos reikšmės, o eksperimentai atlikti apdorojant bandomaji plačiajuosčio ryšio kalbos signalą, kurio pavyzdys paimtas ties $16 \mathrm{kHz}$. Kvantizatorius panaudojamas kaip antras dviejų etapų kvantizacijos sistemų etapas. Šioje sistemoje, pirmasis etapas yra panaudojamas tęstiniam signalo pavyzdžių kaupimui, o antrasis suteikia papildomą duomenų kompresiją. Pagrindinis straipsnio tikslas - aptariant teorinius dviejų kvantavimo modelių rezultatus pateikti patobulintą modelio dizainą. Kadangi tradiciniai veiklos rezultatų ǐvertinimo modeliai leidžia apskaičiuoti vidutinį našumą, autoriai nusprendè pasiūlyti naują veiklos rezultatų įvertinimo modelį ir išsamiai išanalizuoti kiekvieno atsitiktinio įvesties signalo skirtumo duomenis. Eksperimento rezultatai parodè puikų atitikimą su teoriniais rezultatais. 